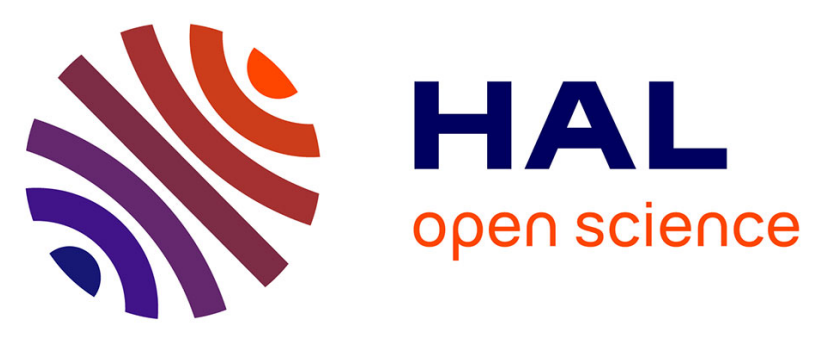

\title{
Generation of Mesoband Signals With Optoelectronic Technique and a Combiner for Intentional Electromagnetic Interference Conducted Tests
}

Jeremy Hyvernaud, Gwenael Reineix, Romain Négrier, Joël Andrieu, Michèle Lalande, Vincent Couderc

\section{To cite this version:}

Jeremy Hyvernaud, Gwenael Reineix, Romain Négrier, Joël Andrieu, Michèle Lalande, et al.. Generation of Mesoband Signals With Optoelectronic Technique and a Combiner for Intentional Electromagnetic Interference Conducted Tests. IEEE Transactions on Electromagnetic Compatibility, 2020, pp.1-10. 10.1109/TEMC.2020.3008291 . hal-03002624

\section{HAL Id: hal-03002624 \\ https://hal.science/hal-03002624}

Submitted on 8 Dec 2020

HAL is a multi-disciplinary open access archive for the deposit and dissemination of scientific research documents, whether they are published or not. The documents may come from teaching and research institutions in France or abroad, or from public or private research centers.
L'archive ouverte pluridisciplinaire HAL, est destinée au dépôt et à la diffusion de documents scientifiques de niveau recherche, publiés ou non, émanant des établissements d'enseignement et de recherche français ou étrangers, des laboratoires publics ou privés. 


\title{
Generation of mesoband signals with optoelectronic technique and a combiner for intentional electromagnetic interference conducted tests
}

\author{
Jérémy Hyvernaud, Gwenaël Reineix, Romain Négrier, Joël Andrieu, Michèle Lalande and Vincent Couderc
}

\begin{abstract}
In this article, a source for generating conducted intentional electromagnetic interference (IEMI) with a mesoband spectrum is presented in order to perform electromagnetic susceptibility tests on electronic equipment. This high voltage source is based on different optoelectronic generators which integrate photoconductive semiconductor switches (PCSS) operating in linear switching mode and triggered by a laser pulse. These optoelectronic devices generate a damped sinusoidal signal with a center frequency between 20 and $200 \mathrm{MHz}$, a $Q$ factor between 11 and 12.4, and a maximum peak-to-peak magnitude of $3.12 \mathrm{kV}$ for a bias voltage of $4 \mathrm{kV}$. An optoelectronic generator model was designed using Advance Design System (ADS) software and experimental tests were performed with a measurement bench to compare simulated and measured results. A study on a voltage increase of these generators has been performed, and has established the experimental limits of generation in planar technology with low-cost PCSS available on the shelf. The highest peak-to-peak magnitude value obtained is $6.10 \mathrm{kV}$ and was possible thanks to the design and manufacture of a power combiner, with ADS and CST Suite Studio softwares, to set up a multi-way combination.
\end{abstract}

Index Terms-Electronic warfare, Intentional electromagnetic interference, Mesoband waveforms, Optoelectronic generators, Photoconductive semiconductor switches, Power combiner.

\section{INTRODUCTION}

$\mathbf{I}$ $\mathrm{N}$ recent decades, intentional electromagnetic interference (IEMI) of non-nuclear origin has become a significant danger with the ubiquity of electronics in our daily lives. In fact, military infrastructures, as well as civil infrastructures considered to be critical, such as electrical, communication or transport networks, are all examples of targets for potential attackers [1], [2]. Successful attacks could have serious consequences [3]-[5]. IEMI can be generated anonymously and at a certain distance from physical barriers; they can also be introduced in two different ways [6]. When the interference signal enters an entry point designed to pass normal signals, such as an antenna, it is a front-door coupling. On the contrary, when the interference signal enters the structure through openings not designed for this, such as the slots around a door, it is a back-door coupling. Disrupting the communication of a mobile phone with a jammer is therefore an example of a front-door radiated attack. However, the creation of a strong electromagnetic field which crosses the walls of a building

J. Hyvernaud, G. Reineix, R. Négrier, J. Andrieu, M. Lalande and V. Couderc was with the Xlim laboratory, University of Limoges, Limoges, France.

e-mail : jeremy.hyvernaud@unilim.fr to damage computers is an example of a radiated back-door attack.

In Fig. 1 [7]-[9], the frequency spectra of electric fields due to lightning, electromagnetic pulse generated by the explosion of a nuclear bomb at high altitude (HEMP), usual interference (industrial noise, radios...), and IEMI, are compared. The radiated IEMI are represented on the right of the figure. They are generally included in a frequency range going from a few hundred MHz to a few GHz. Their spectrum can take different forms: ultra-wideband, mesoband or narrowband (for example high power microwaves (HPM)). The variety and extension of bandwidth, as well as the differences between IEMI and more conventional interference make it difficult to use conventional EMC protections. As for the conducted IEMI, they can contain low frequencies (or even direct current) and are limited at high frequency by the characteristics of the cabling in which they are propagated.

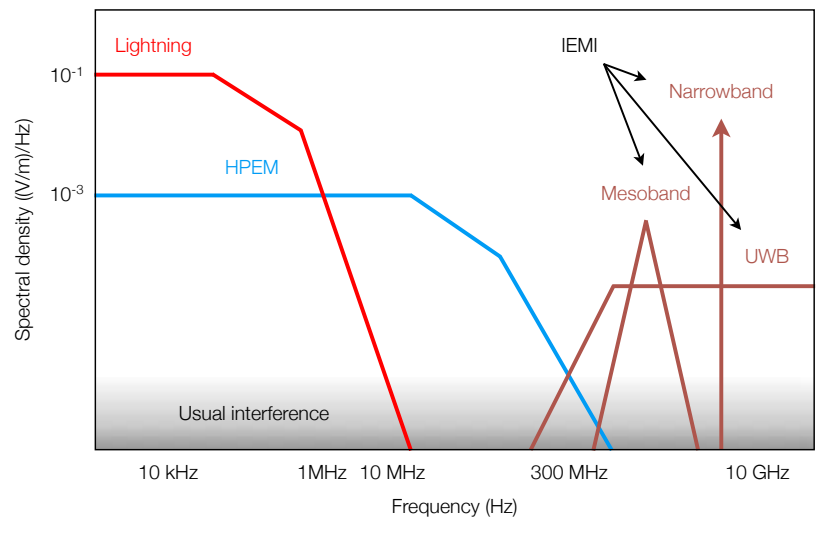

Fig. 1. Positions of the different threats in the spectral environment.

There are currently many sources of interference available, such as high-power electromagnetic sources (HPEM) which can reach several hundred kilovolts [10], [11]. In this context, it is then necessary to examine the threats [12], to identify the main characteristics of the infrastructures on which our society depends [13], to test protection strategies [14], to carry out simulations and measurements, and finally, to condense the results into recommendations accessible to a large audience. The need targeted in this study is integrated into the vulnerability of electronic systems through the generation of conducted IEMI with a spectral component of mesoband type. The source developed is based on the technology of 
optoelectronic generators made up of photoconductive semiconductor switches (PCSS). These components are suitable for generating particular waveforms of several kilovolts, and with a rise time of several tens of picoseconds [15], [16]. The objectives are to generate damped sinusoidal signals whose frequency varies between 20 and $200 \mathrm{MHz}$, with a minimum $\mathrm{Q}$ factor equal to 10 , as well as a peak-to-peak magnitude of $10 \mathrm{kV}$ on a load of $50 \Omega$ impedance. The article is structured as follows: Section II focuses on the design of damped sinusoids optoelectronic generators; Section III presents a study on a voltage increase of these generators through different technical solutions; finally, section IV concludes by setting out the obtained results.

\section{DESIGN OF DAMPED SINUSOIDS OPTOELECTRONIC GENERATORS}

The work carried out in [17] led to the design of damped sinusoids optoelectronic generators (see Fig. 2). These generators are made up of GP02-40 PCSS, marketed by Vishay, placed on either side of a microstrip line charged by a high voltage power supply. They are made of silicon and have a maximum bias voltage of $4 \mathrm{kV}$ and a current limit of $0.25 \mathrm{~A}$.

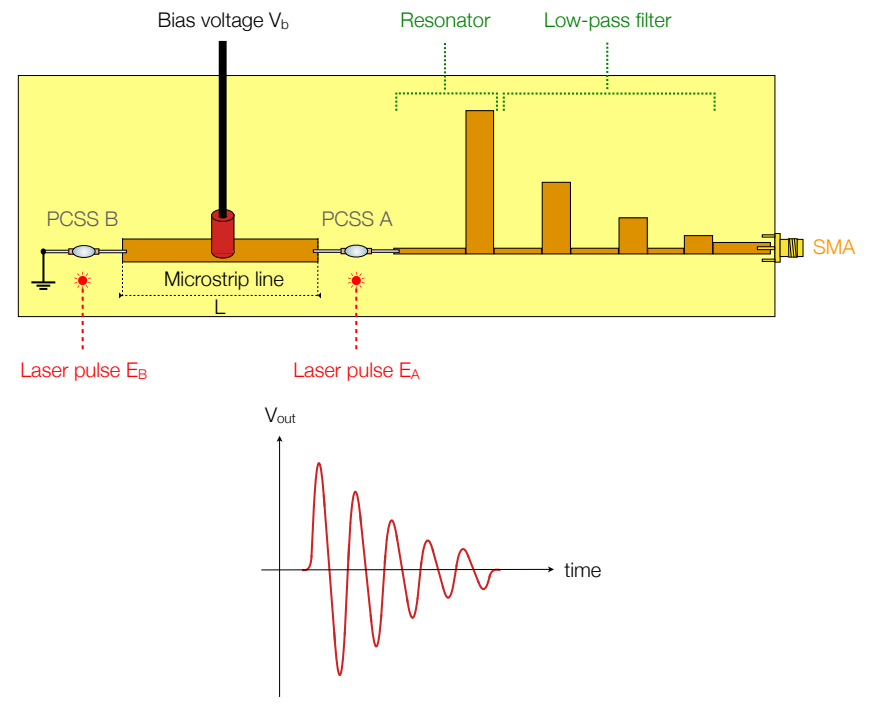

Fig. 2. Damped sinusoids optoelectronic generator.

\section{A. Operation of PCSS and optoelectronic generators}

The operation of a PCSS is as follows: in the initial state, the component has a strong $R_{o f f}$ impedance (several $\mathrm{M} \Omega$ ), equivalent to an open switch. When the PCSS is illuminated with a $1064 \mathrm{~nm}$ laser pulse, it goes from an insulation state to a conduction state, equivalent to a closed switch. During this conduction state, its impedance decreases to a $R_{\text {on }}$ value of 1 $\Omega$ during a $t_{o n}$ conduction time. After this state, a charge carrier recombination phenomenon appears and allows the PCSS to recover its initial state (see Fig. 3).

A $1064 \mathrm{~nm}$ laser pulse applied simultaneously on both PCSS of the optoelectronic generator in Fig. 2 drops their impedance and allows the ultrafast release of the high-voltage

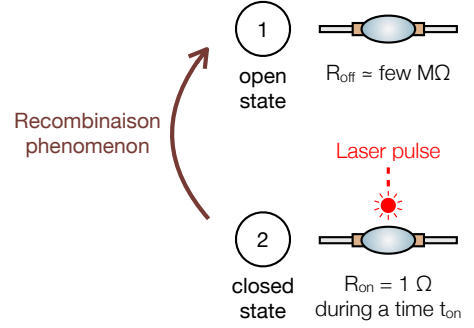

Fig. 3. Operation of a PCSS.

static field, confined on the microstrip line, in the form of a progressive wave and of a regressive wave. The reflection of the regressive wave at the PCSS B located near the ground induces an inversion of its polarity. A linear superposition of these two waves forms, after the PCSS A, a bipolar electric pulse. A microstrip line associated to a stub, as presented in [18], introduces the resonance phenomenon; the bipolar electric pulse is therefore maintained over time to obtain a damped sinusoid. Then, a series of three microstrip lines/stubs, equivalent to a low-pass filter [19], smoothes the shape of the obtained output signal.

\section{B. Damped sinusoids optoelectronic generator model}

Fig. 4 represents the realized model with Advance Design System (ADS) software where each microstrip line and each stub have been implemented. Both PCSS are considered with a on-state impedance of $1 \Omega$ in the closed state. The bias voltage $V_{b}$ applied to the microstrip line between the PCSS is modeled by a pulse source and the large value of the resistor $R_{1}$ prevents from any reflection. The output signal, measured on the load resistor $R_{2}$, is acquired once the microstrip line is fully charged and after closing the two switches. The substrate used is epoxy resin (FR-4) which has a thickness of $1.5 \mathrm{~mm}$, a relative dielectric constant of 4.3 and a dielectric loss tangent of 0.02 .

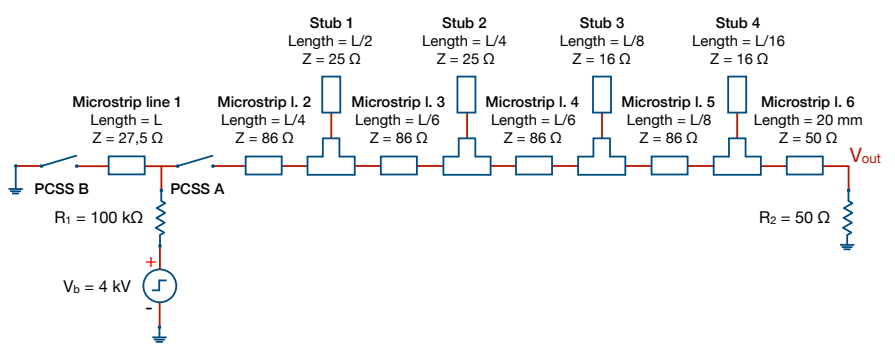

Fig. 4. ADS model of the damped sinusoids optoelectronic generator.

Transient optimization of the output signal shape has been used to calculate the length and impedance of each line and stub. Goals to be achieved are:

- stick as close as possible to the transient shape of a reference damped sinusoid (1),

- obtain the best ratio between applied bias voltage and peak-to-peak magnitude of the output signal,

- obtain the highest value of the $\mathrm{Q}$ factor. 


$$
x(t)=A \cdot \sin (2 \pi f t) \cdot \exp (\lambda t)
$$

The values shown in Fig. 4 are the result of the optimization. Each length is expressed as a function of the initial length $\mathrm{L}$ of the first microstrip line. This ADS model is valid on the frequency band (20-200 MHz); the center frequency $f_{c}$ of the damped sinusoidal signal obtained depends on the length $\mathrm{L}$ and empirical analyzes reveal that (2). The units of $\mathrm{L}$ and $f_{c}$ are respectively the meter and the hertz, while $\mathrm{K}$ is a constant equal to $10^{7.75} \mathrm{~m} . \mathrm{Hz}$.

$$
L=\frac{K}{f_{c}}
$$

Fig. 5 compares the simulated and reference signals. The simulated signal fulfills the requirements of the three desired goals; its transient shape is superimposed as closely as possible to the reference damped sinusoid with a highest value possible of the $\mathrm{Q}$ factor, here $\mathrm{Q}=10$. Two differences are nevertheless to be noted:

- the magnitude of the first negative maximum of the simulated signal has a higher value: it is a trade-off between the respect of the transient shape and the goal of achieving the best ratio between the peak-to-peak magnitude and the bias voltage. This ratio varies between $51 \%$ and $73 \%$ over the frequency band (20-200 MHz). At best, we obtain a peak-to-peak magnitude of $2.9 \mathrm{kV}$ for $4 \mathrm{kV}$ bias voltage.

- the spectrum of the signals obtained by simulation has low frequency components with a higher level compared to the spectrum of the reference signal; this is caused by the first alternations of the simulated damped sinusoid which have a lower center frequency than desired. However the level of these components is negligible since it is close to $-10 \mathrm{~dB}$ compared to the center frequency peak.

\section{Measurement bench and results}

Two damped sinusoids optoelectronic generators have been realized with $1.5 \mathrm{~mm}$ thick epoxy resin substrate (FR-4) to validate the simulations on the given frequency band (see Fig. 6). The first one has a center frequency $f_{c}$ of $28 \mathrm{MHz}$ for dimensions of $220 \mathrm{~mm} \times 510 \mathrm{~mm}$, and the second one has a center frequency $f_{c}$ of $178 \mathrm{MHz}$ for dimensions of $220 \mathrm{~mm}$ x $170 \mathrm{~mm}$.

Fig. 7 shows the measurement bench used to generate the damped sinusoidal signals. An Ekspla PL2250 laser source delivers 80 ps pulses with a repetition rate of $10 \mathrm{~Hz}$ in the infrared range $(1064 \mathrm{~nm})$. The laser beam is separated into two adjustable parts using a beam splitter cube (BSC), and the distribution of the optical energy is adjusted with a half wave plate (HWP) to obtain the same illumination of the two PCSS. Adjustable mirrors $\left(M_{1}, M_{2}\right.$ and $\left.M_{3}\right)$ are arranged after the splitter cube to equalize the length of the different optical paths. The damped sinusoids optoelectronic generator has been powered by a high voltage power supply of $4 \mathrm{kV}$. For the acquisition of the output signal, a Barth attenuation chain of 68 dB and a Keysight DSOX92004Q Infiniium oscilloscope have
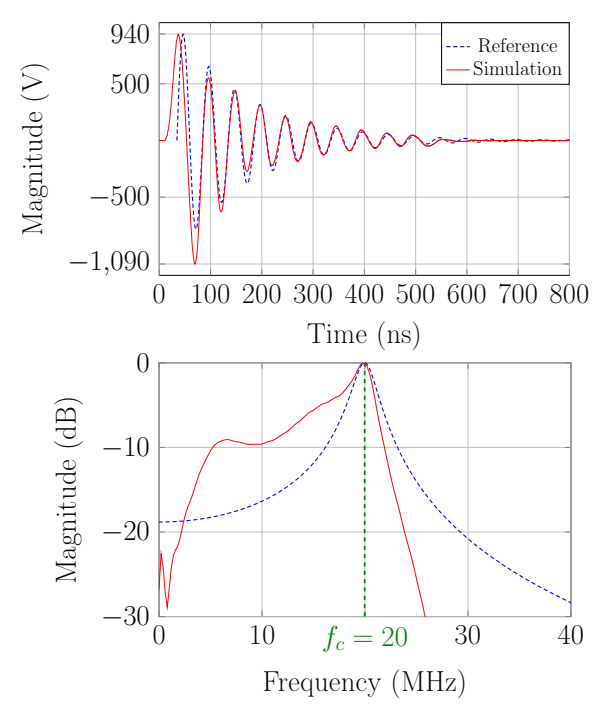

(a)
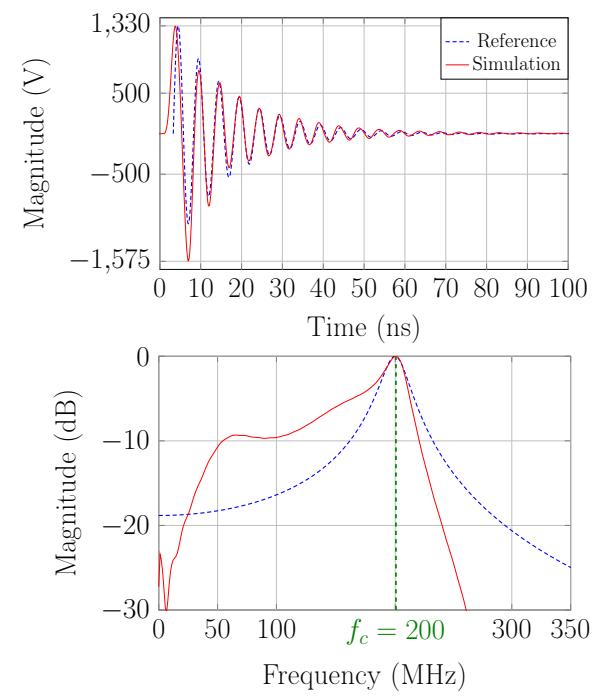

(b)

Fig. 5. Output signal optimization compared to the reference signal. (a) Optoelectronic generator at $f_{c}=20 \mathrm{MHz}$; (b) Optoelectronic generator at $f_{c}=200 \mathrm{MHz}$.

been used. It operates in real time with an $8 \mathrm{GHz}$ bandwidth and an acquisition time of $20 \mathrm{GSa} / \mathrm{s}$.

Fig. 8 compares the signals obtained by simulation to those obtained experimentally. The very good superposition of the curves allows to validate the ADS model of the damped sinusoids optoelectronic generator (Fig. 4):

- the measured signal with a center frequency $f_{c}$ of 28 $\mathrm{MHz}$ has a peak-to-peak magnitude of $2.5 \mathrm{kV}$ (63\% of the bias voltage) and a $\mathrm{Q}$ factor of 10.6.

- the measured signal with a center frequency $f_{c}$ of 178 $\mathrm{MHz}$ has a peak-to-peak magnitude of $2.9 \mathrm{kV}$ (73\% of the bias voltage) and a $\mathrm{Q}$ factor of 10.1.

At this point, two of the three objectives have been achieved. With the optoelectronic generators developed, it is possible to generate damped sinusoids between 20 and $200 \mathrm{MHz}$ with a minimum $\mathrm{Q}$ factor equal to 10 . Only the third objective 


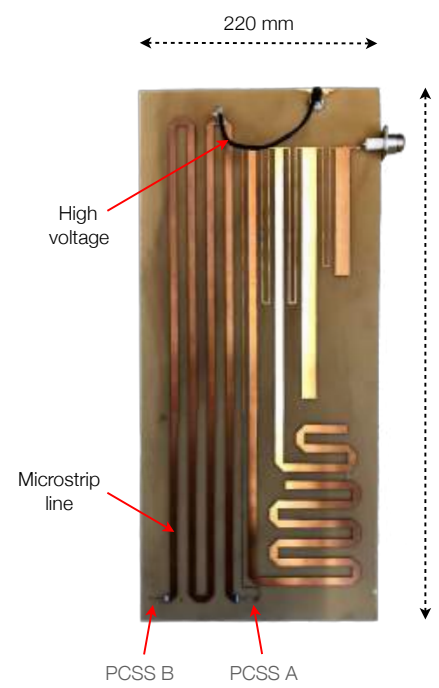

(a)

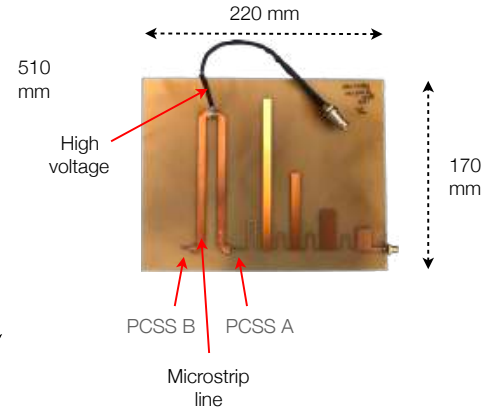

(b)
Fig. 6. Realization of two damped sinusoids optoelectronic generators. (a) $f_{c}=28 \mathrm{MHz}$; (b) $f_{c}=178 \mathrm{MHz}$.

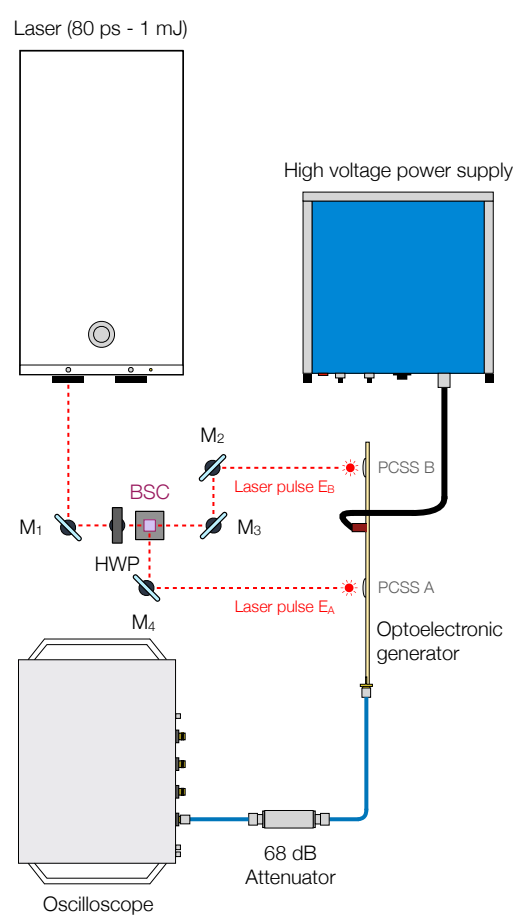

Fig. 7. Measurement bench to generate damped sinusoids; M: Reflective Mirror; HWP: Half Wave Plate; BSC: Beam Splitter Cube.

relating to the peak-to-peak magnitude value of $10 \mathrm{kV}$ is not satisfied since the maximum value obtained is $2.9 \mathrm{kV}$.

\section{VOLTAGE INCREASE}

The GP02-40 PCSS used so far have a maximum bias voltage of $4 \mathrm{kV}$ as a limitation. The rest of the work is focused on a voltage increase in order to reach the highest possible peak-to-peak magnitude value. Several solutions have been studied:

- associate GP02-40 PCSS in series,
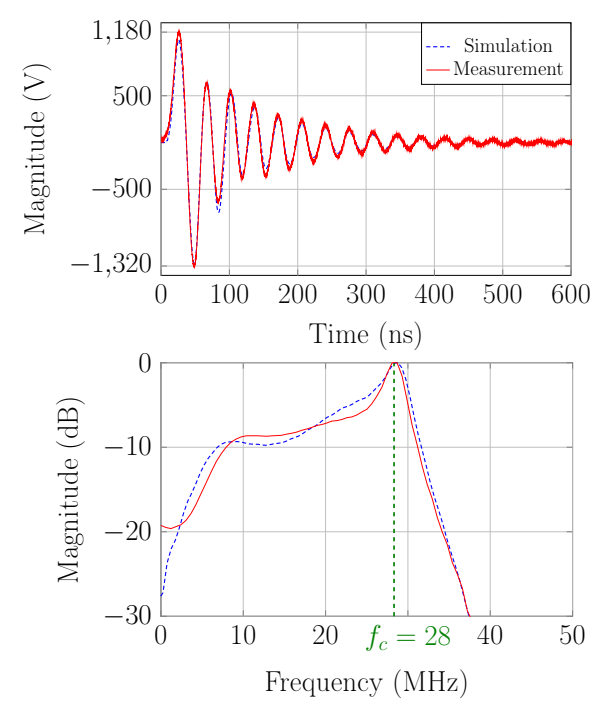

(a)
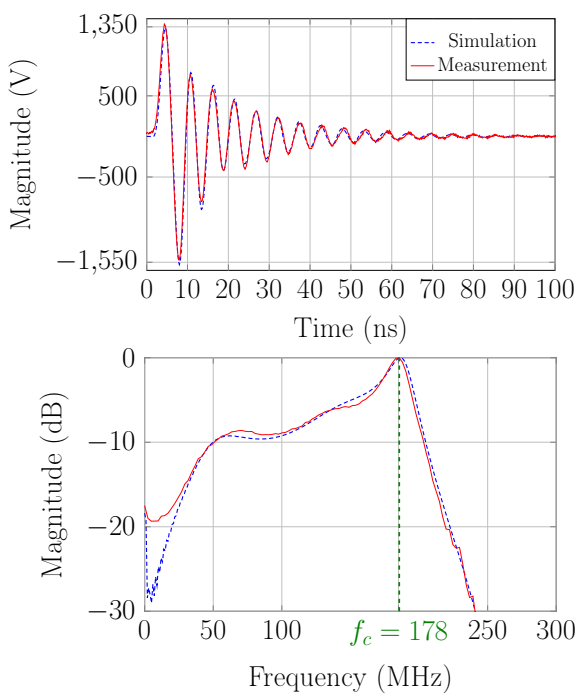

(b)

Fig. 8. Comparison of simulated and experimental signals. (a) Optoelectronic generator at $f_{c}=28 \mathrm{MHz}$; (b) Optoelectronic generator at $f_{c}=178 \mathrm{MHz}$.

- use PCSS with a maximum bias voltage equal to $15 \mathrm{kV}$,

- design and manufacture a power combiner.

\section{A. Laser change}

In order to be able to perform these different solutions, a more suitable laser is necessary. Indeed, the Ekspla PL2250 laser has an insufficient energy of $1 \mathrm{~mJ}$, which does not allow the desired tests to be carried out. A laser like the Ekspla SL300, which has a pulse duration of $150 \mathrm{ps}$ as well as a maximum energy of $50 \mathrm{~mJ}$, is a better equipment choice. One of the notable differences between these two lasers, apart from the pulse duration and maximum energy, is the diameter of the illumination beam which is more important for the $150 \mathrm{ps}$ laser (see Fig. 9). To try this new laser, the experiments with the two previous damped sinusoids optoelectronic generators were repeated. 


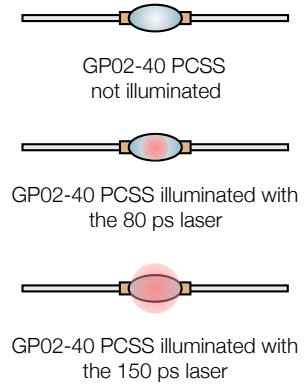

Fig. 9. Illumination difference depending on the laser used.

A significant improvement is notable, whether in terms of peak-to-peak magnitude, $\mathrm{Q}$ factor and spectrum. For the first optoelectronic generator at $f_{c}=28 \mathrm{MHz}$, the peak-topeak magnitude increases from $2.50 \mathrm{kV}$ to $2.98 \mathrm{kV}$, and the Q factor from 10.6 to 11 (see Fig. 10 (a)). For the second optoelectronic generator at $f_{c}=178 \mathrm{MHz}$, the peakto-peak magnitude increases from $2.90 \mathrm{kV}$ to $3.12 \mathrm{kV}$, and Q factor from 10.1 to 12.4 (see Fig. 10 (b)). The level of the low frequency components of the two new spectra are more attenuated and are around $-11 \mathrm{~dB}$. This indicates that a homogeneous distribution of the illumination on the total surface of the PCSS makes it possible to decrease its $R_{o n}$ impedance below $1 \Omega$. Based on this observation, the $150 \mathrm{ps}$ laser is used for the following tests.

\section{B. GP02-40 PCSS in series}

A first solution to achieve a voltage increase is to combine two GP02-40 PCSS in series (see Fig. 11). The maximum voltage applicable to the terminals of the components is then $8 \mathrm{kV}$. The use of divergent and cylindrical lenses is necessary to be able to uniformly illuminate the two pairs of PCSS in series.

The following results were obtained for the damped sinusoids optoelectronic generator at $f_{c}=28 \mathrm{MHz}$ (see Fig. 12). For a bias voltage $V_{b}$ of $4 \mathrm{kV}$, the same signal as that presented in Fig. 10 (a) is obtained. The only difference is that here the optical energy applied is higher in order to be able to shape an illuminating surface in line with the serialization. However, for a bias voltage $V_{b}$ of $5 \mathrm{kV}$, the desired signal can not be obtained. Indeed, only the first alternation has an increase in its voltage level, the peak-to-peak magnitude goes from 2.95 $\mathrm{kV}$ to $3.31 \mathrm{kV}$. The $\mathrm{Q}$ factor is therefore slightly lower and decreases from 10.8 to 10.7. The low frequency components of the spectrum are no longer less than $-10 \mathrm{~dB}$.

The signal at $V_{b}=5 \mathrm{kV}$ makes it possible to deduce that the $R_{o n}$ impedance is no longer less than or equal to $1 \Omega$, and does not allow the expected linear increase. An attempt to observe the evolution of the phenomenon at a bias voltage $V_{b}$ of $6 \mathrm{kV}$ could not be carried out because one of the couples of PCSS in series did not support this increase in voltage. For better reliability, the use of PCSS supporting a higher bias voltage should be preferred.
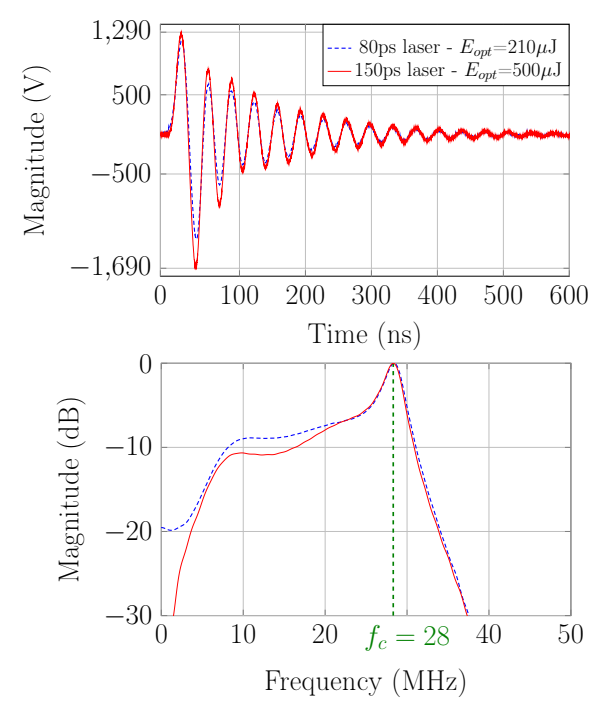

(a)
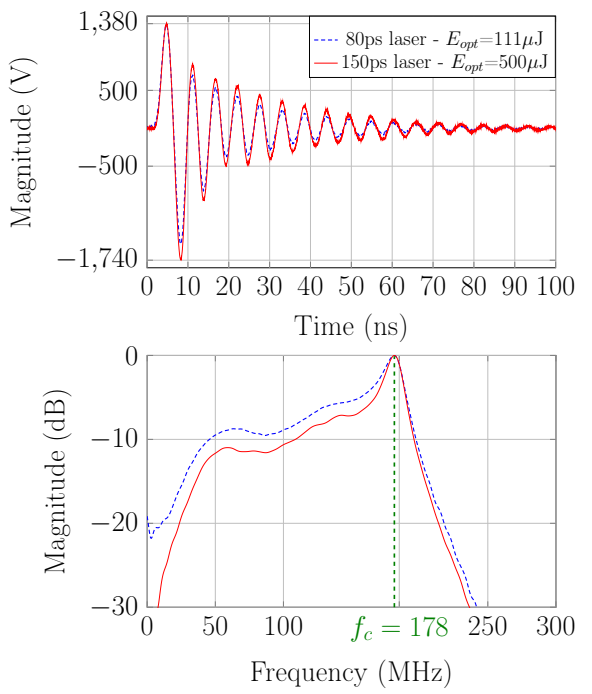

(b)

Fig. 10. Comparison of the signals obtained for each laser. (a) Optoelectronic generator at $f_{c}=28 \mathrm{MHz}$; (b) Optoelectronic generator at $f_{c}=178 \mathrm{MHz}$.

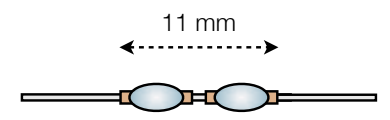

Fig. 11. GP02-40 PCSS in series.

\section{New PCSS reference: OZ150SG}

As a second solution, a new PCSS reference was ordered, the OZ150SG model marketed by Voltage Multipliers Inc. (see Fig. 13). It is also composed of silicon and has a maximum bias voltage of $15 \mathrm{kV}$ and a current limit of $0.3 \mathrm{~A}$

A first attempt was to compare the two PCSS references for a bias voltage $V_{b}$ of $4 \mathrm{kV}$ (see Fig. 14). The two signals obtained are almost identical, as are the peak-to-peak magnitude and Q factor values. The spectrum with the GP02-40 PCSS is slightly better because the low frequency components are more attenuated. It should be noted that the OZ150SG PCSS require 

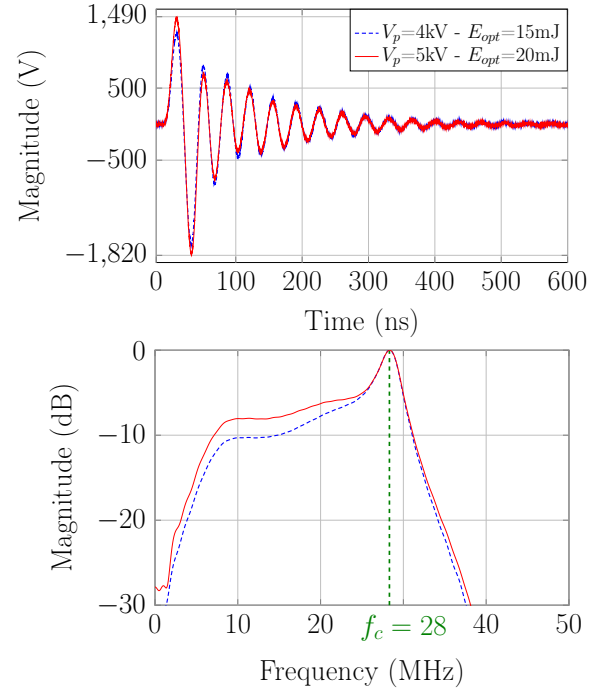

Fig. 12. Signals obtained with two GP02-40 PCSS in series for a bias voltage $V_{b}$ of 4 and $5 \mathrm{kV}$.

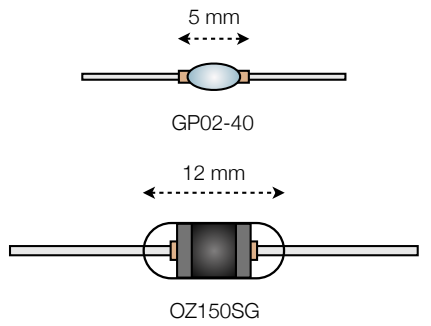

Fig. 13. Comparison of the two PCSS references.

much more optical energy to obtain an identical signal. The reason comes from the geometry of the component which has a much larger silicon surface to illuminate (divergent lenses required).
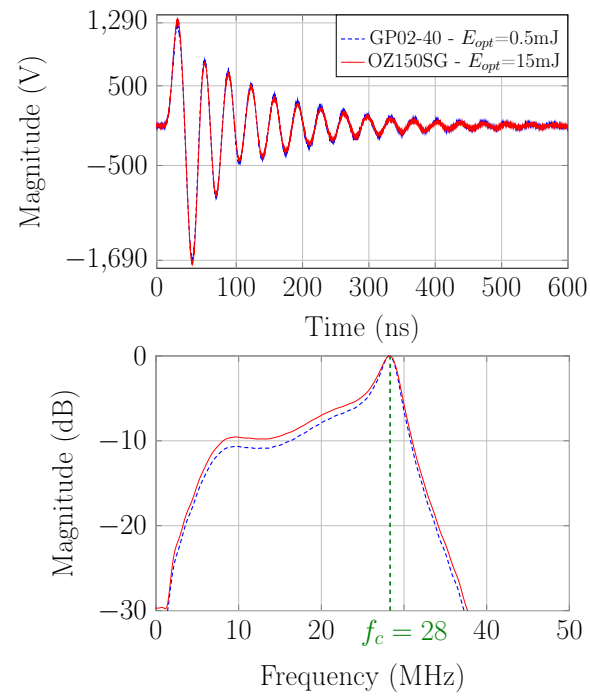

Fig. 14. Comparison of the signals obtained for each PCSS for a bias voltage $V_{b}$ of $4 \mathrm{kV}$.

The OZ150SG reference was then tested at a bias voltage $V_{b}$ of 5 and $6 \mathrm{kV}$. The same phenomenon previously mentioned for serialization is observed, and is more visible for a bias voltage $V_{b}$ of $6 \mathrm{kV}$. For the first variation from 4 to $5 \mathrm{kV}$, the peak-to-peak magnitude increases from 3.1 to $3.4 \mathrm{kV}$ and the Q factor decreases from 9.4 to 9 (see Fig. 15 (a)); and for the second variation from 5 to $6 \mathrm{kV}$, the peak-to-peak magnitude increases from 3.4 to $4.4 \mathrm{kV}$ and the $\mathrm{Q}$ factor decreases from 9 to 8.4 (see Fig. 15 (b)).
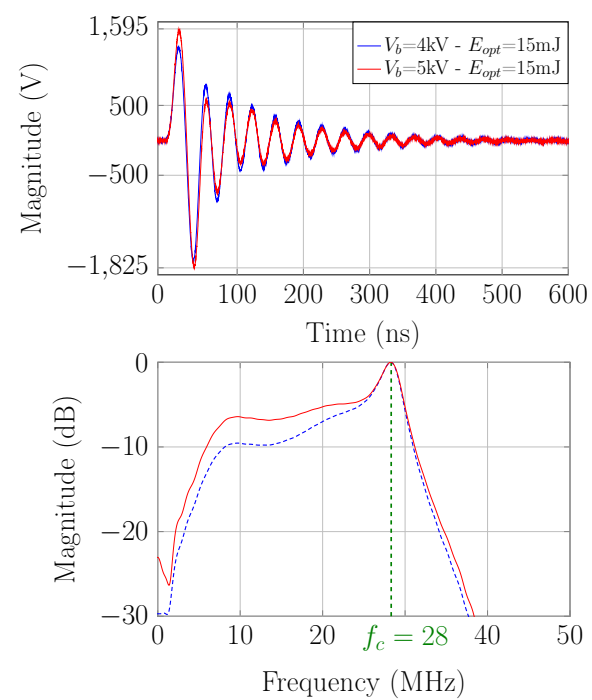

(a)
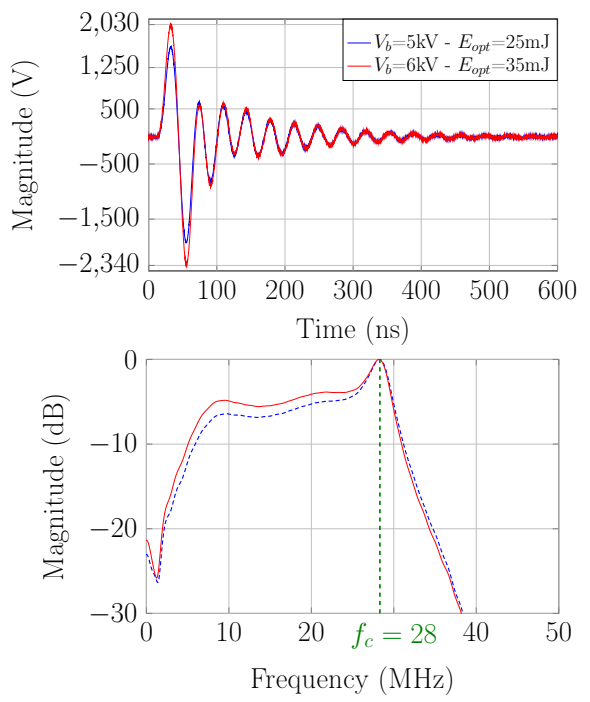

(b)

Fig. 15. Comparison of signals obtained with a OZ150SG PCSS. (a) for a bias voltage $V_{b}$ of 4 and $5 \mathrm{kV}$; (b) for a bias voltage $V_{b}$ of 5 and $6 \mathrm{kV}$.

Whatever damped sinusoids optoelectronic generator is used, increasing the level of the bias voltage $V_{b}$ above 4 $\mathrm{kV}$ leads to a drop in the $\mathrm{Q}$ factor and an increase in the level of the low frequency components, despite higher applied optical energy. This non-linear phenomenon can be explained by the Franz-Keldysh effect which results in a modification of the optical absorption by a semiconductor when an excessive electric field is applied. The PCSS used, beyond a bias voltage $V_{b}$ of $4 \mathrm{kV}$, are therefore no longer perfectly suited 
to be illuminated with a $1064 \mathrm{~nm}$ laser pulse, which leads to a progressive increase of the $R_{o n}$ impedance. For a bias voltage $V_{b}$ of $6 \mathrm{kV}$, the impedance was evaluated at $3 \Omega$ by retro-simulation. To obtain signals in line with the fixed requirements, it is essential to maintain a $R_{o n}$ impedance less than or equal to $1 \Omega$. The best tradeoff is then to use GP0240 PCSS polarized at $4 \mathrm{kV}$, and illuminated with the $150 \mathrm{ps}$ laser, because it is this configuration which allows to obtain the lowest $R_{o n}$ impedance (see Fig. 16).

\begin{tabular}{|c|c|c|}
\hline & 80 ps laser (1 mJ) & 150 ps laser (50 mJ) \\
\hline GP02-40 & $R_{o n} \simeq 1 \Omega$ & $\mathrm{R}_{\mathrm{on}}<1 \Omega$ \\
\hline \multirow{3}{*}{$\begin{array}{c}\text { GP02-40 in series } \\
\text { OZ150SG }\end{array}$} & \multirow{3}{*}{$\begin{array}{l}\text { non-optimal } \\
\text { illumination and too } \\
\text { low energy }\end{array}$} & $R_{o n} \simeq 1 \Omega$ for $V_{b} \in[0-4] \mathrm{kV}$ \\
\hline & & $R_{o n}>1 \Omega$ for $V_{b}>4 k V$ \\
\hline & & Franz-Keldysh effect \\
\hline
\end{tabular}

Fig. 16. Value of the $R_{o n}$ impedance of the different PCSS according to the laser used.

\section{Design of a 4-way power combiner}

The third solution to achieve a voltage increase is to design a power combiner where each of its inputs will be connected to an identical damped sinusoids optoelectronic generator (see Fig. 17); the very low jitter ( $\leq 2 \mathrm{ps})$ linked to optoelectronic technology would make it possible to illuminate all PCSS at the same time. The number of inputs for the combiner has been fixed at four for hardware limitations; with this number of inputs, the theoretical voltage multiplication factor is two.

To perform an ideal summation for IEMI tests, the combiner must present:

- a bandwidth between 20 and $200 \mathrm{MHz}$

- a peak-to-peak voltage level admissible at the output of $10 \mathrm{kV}$,

- a reflection coefficient on each input and on the output less than $-10 \mathrm{~dB}$,

- a transmission coefficient between the inputs less than $-10 \mathrm{~dB}$,

- the highest possible transmission coefficient between each input and the output.

Following a state of the art of the various power combiner technologies, the coaxial waveguide technology was chosen for its voltage withstand and its simplicity of manufacture. The components of a coaxial waveguide combiner are similar to those of a coaxial cable, namely an inner conductor, a dielectric, and an outer conductor. The material used to make the two conductors is aluminum $\left(\rho=2.65 .10^{-8} \Omega . \mathrm{m}\right)$, while the material chosen for the dielectric is PTFE $\left(\epsilon_{r}=2.1\right.$, $\left.\tan \delta=2.10^{-4}, E_{\max }=60 \mathrm{MV} \cdot \mathrm{m}^{-1}\right)$. These two materials were selected for their machining simplicity and their physical properties.

The outside diameter of the dielectric has been set at $60 \mathrm{~mm}$ in order to have enough space to implement four $50 \Omega \mathrm{N}$ input connectors. An impedance matching is necessary in order to go

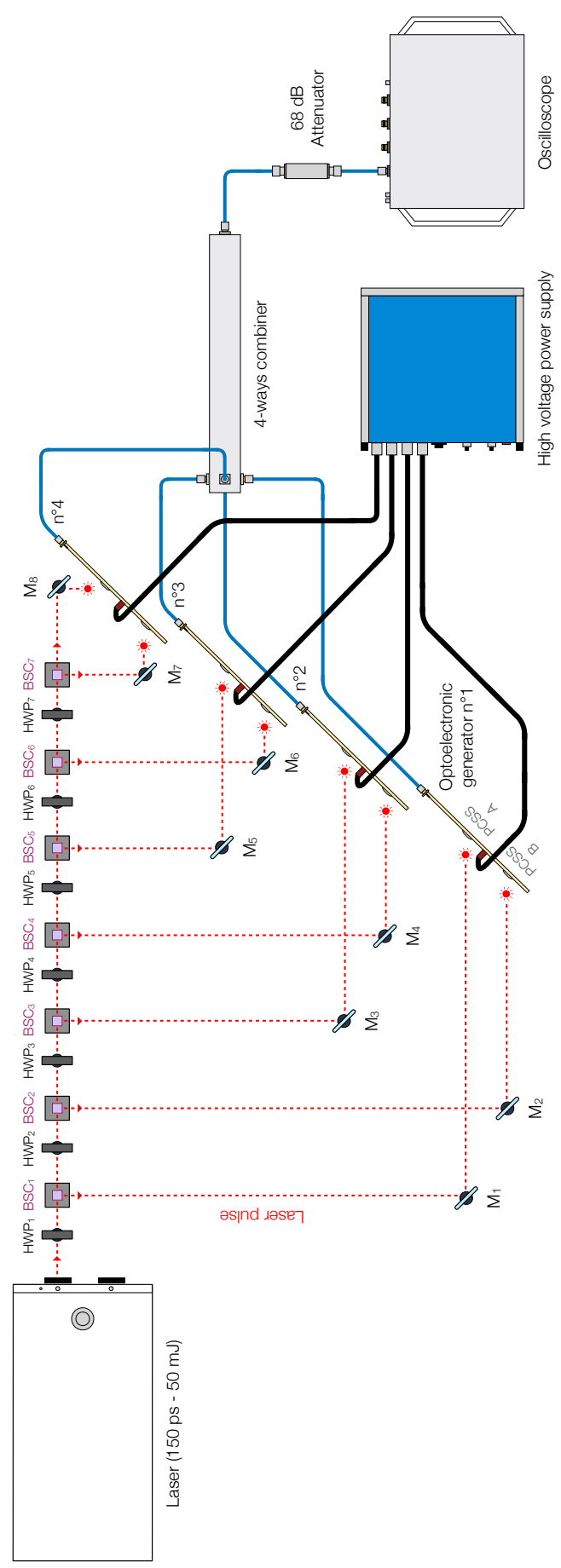

Fig. 17. Measurement bench for carrying out a voltage increase using a power combiner. M: Reflective Mirror; HWP: Half Wave Plate; BSC : Beam Splitter Cube.

from an equivalent impedance line of $12.5 \Omega$ to an equivalent impedance line of $50 \Omega$. This impedance matching was carried out using an ADS model in order to obtain the best bandwidth and the best $\mathrm{S}$ parameters for a structure length which does not exceed one meter (see Fig. 18). The optimization on the $\mathrm{S}$ parameters made it possible to define the overall geometry of the combiner and to obtain the following simulation results (see Fig.19 - simulation curve). The maximum bandwidth that 
can be achieved for a length of one meter is $(66.5-278 \mathrm{MHz})$. Transmission losses range from $-0.05 \mathrm{~dB}$ to $-0.45 \mathrm{~dB}$, while the insulation between the inputs is $-11.3 \mathrm{~dB}$ minimum.

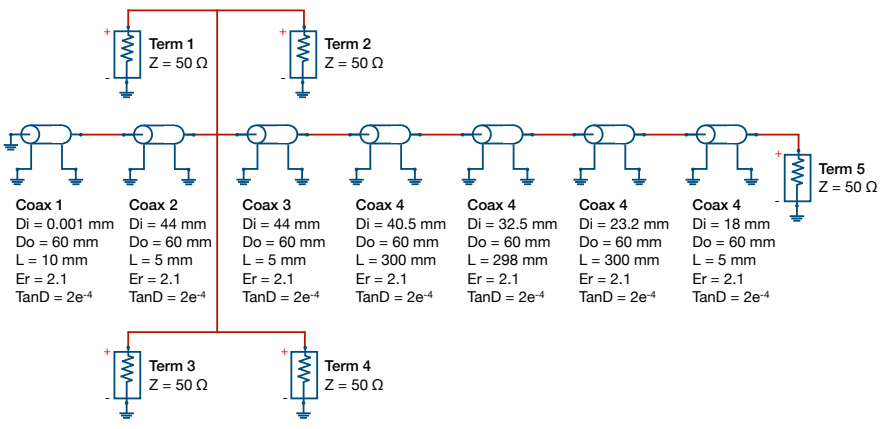

Fig. 18. ADS model of the power combiner.
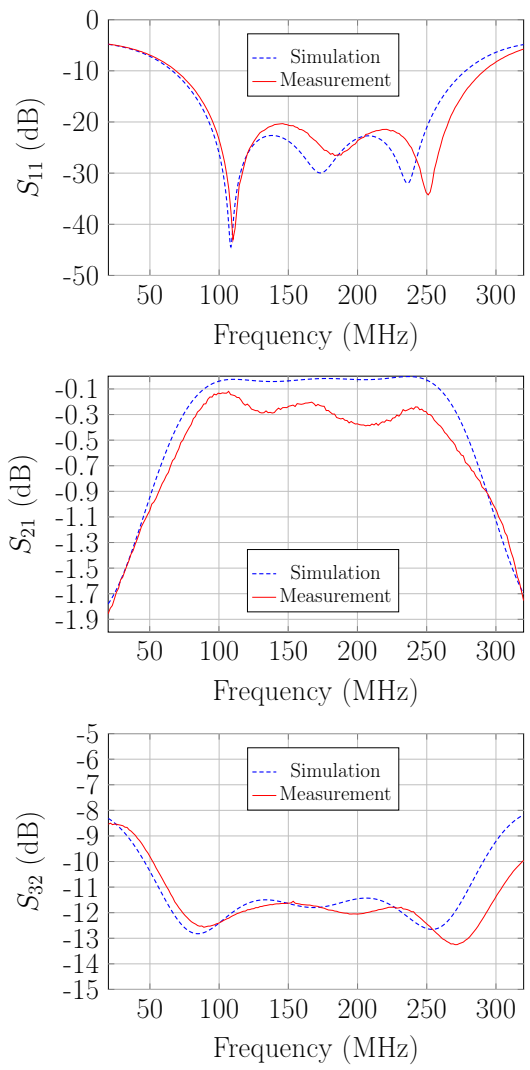

Fig. 19. Comparison of simulated and experimental results of the $\mathrm{S}$ parameters of the power combiner. (a)

A CST Studio Suite model of the combiner has been developed in order to prevent the risks of breakdown voltage in the structure (see Fig. 20). The maximum electric field is 7.3 MV. $m^{-1}$ and is located at the connectors. There is, a priori, no risk of breakdown voltage since the disruptive electric field of PTFE is $60 \mathrm{MV} . \mathrm{m}^{-1}$. The combiner was then modeled for manufacturing (see Fig. 21); the S parameters were checked with a network analyzer (see Fig. 19 - measurement curve). Results very close to the simulation were measured: the bandwidth is (69 - $291 \mathrm{MHz}$ ), the transmission losses range from $-0.12 \mathrm{~dB}$ to $-0.86 \mathrm{~dB}$, and the insulation between the inputs is $-11.7 \mathrm{~dB}$ maximum.

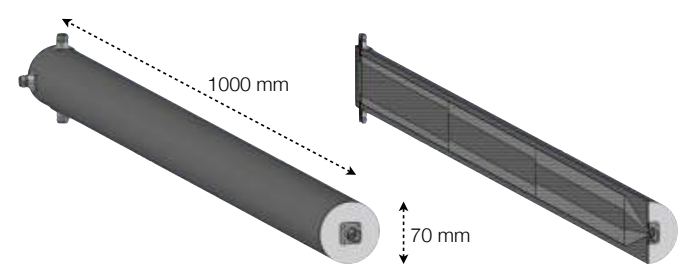

Fig. 20. CST Suite Studio model of the power combiner.

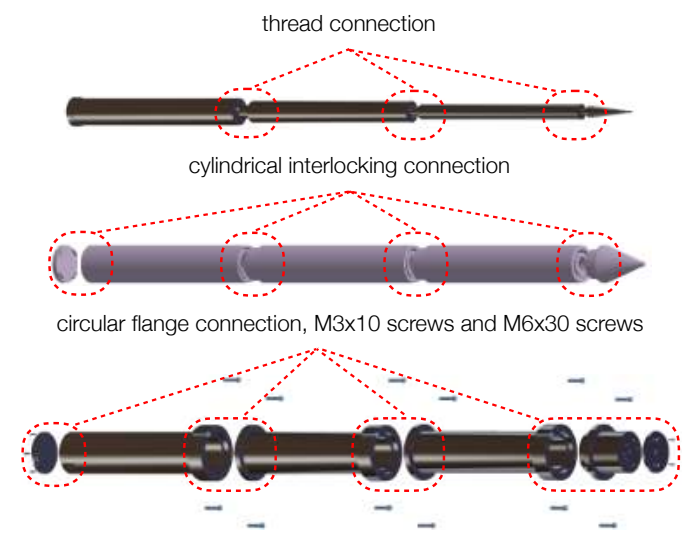

Fig. 21. Power combiner assembly.

The measurement bench in Fig. 17 was then set up; each input of the combiner is connected to a damped sinusoids optoelectronic generator with a center frequency $f_{c}$ of 178 MHz. A bias voltage $V_{b}$ of $4 \mathrm{kV}$ is applied to each generator, while the $150 \mathrm{ps}$ laser, coupled with various optical elements (mirrors, half-wave plates and splitter cubes), make it possible to simultaneously illuminate the 8 PCSS. Fig. 22 shows the output signal obtained after summation. For a center frequency $f_{c}$ of $178 \mathrm{MHz}$, the efficiency measured is $98 \%$. The peakpeak magnitude varies from $3.12 \mathrm{kV}$ for one generator, to a peak-to-peak magnitude of $6.10 \mathrm{kV}$ for four generators. The $\mathrm{Q}$ factor and the spectrum of the output signal are identical to those of the input signal $(\mathrm{Q}=12.4)$; only a defect in the transient shape is visible, this is caused by a reflection probably resulting from the manufacturing.

\section{Conclusion}

The optoelectronic generators technology coupled with a multi-way combination makes it possible to generate mesoband conducted intentional electromagnetic interference (damped sinusoids) in the frequency band $(20-200 \mathrm{MHz})$, with a $\mathrm{Q}$ factor between 11 and 12.4, and a maximum peakto-peak magnitude of $6.10 \mathrm{kV}$.

According to the classifications of IEMI sources established by Giri, Tesche, Sabath and Garbe, our source can be classified by the criteria of source availability [7] and source transportability [20]. With the technologies we use, such as laser, optical elements, high voltage power supply, PCSS and microstrip lines, we classify our source as a medium technological 

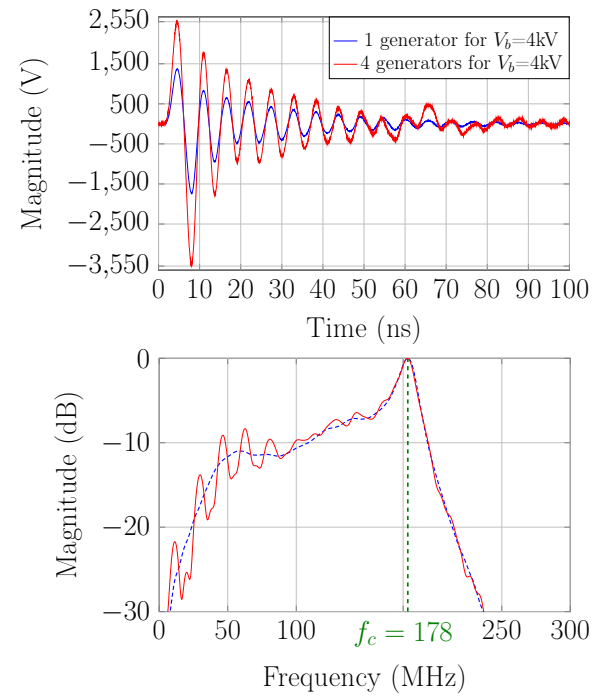

Fig. 22. Comparison between input signal and output signal obtained after summation.

systems with a moderate cost, and as a transportable source. The last criterion can be improved in a mobile source if we equip our laser with a fiber optic output to dispense with the reflecting mirrors, half wave plates and beam splitter cubes.

The prospects for improvement will be to reach the desired peak-to-peak magnitude of $10 \mathrm{kV}$. Two approaches are to be studied.

- The multi-way combinaison can be kept by dimensioning a power combiner with 8 inputs; 16 PCSS would have to be illuminated simultaneously to double the value of $6.10 \mathrm{kV}$ obtained previously.

- The impact of the Franz-Keldysh effect is to be confirmed above $4 \mathrm{kV}$ of polarization. It would be interesting to illuminate the OZ150SG PCSS with a laser which has a variable wavelength, for example the Ekspla PhotoSonus $\mathrm{X}$ model (tuning from 665 to $2600 \mathrm{~nm}$ ), in order to see if it is possible to re-obtain a $R_{o n}$ impedance close to 1 $\Omega$.

\section{ACKNOWLEDGMENT}

The authors would like to thank the French Armament procurement Agency DGA and the French Alternative Energies and Atomic Energy Commission CEA for their funding.

\section{REFERENCES}

[1] W. A. Radasky, C. E. Baum, and M. W. Wik, "Introduction to the special issue on high-power electromagnetics (hpem) and intentional electromagnetic interference (iemi)," IEEE Transactions on Electromagnetic Compatibility, vol. 46, no. 3, pp. 314-321, 2004.

[2] R. Montano, M. Backstrom, D. Mansson, and R. Thottappillil, "On the response and immunity of electric power infrastructures against iemi - current swedish initiatives," in 2008 Asia-Pacific Symposium on Electromagnetic Compatibility and 19th International Zurich Symposium on Electromagnetic Compatibility, pp. 510-513, 2008.

[3] D. Watts, "Security and vulnerability in electric power systems," in 35th North American Power Symposium, University of Missouri-Rolla, Rolla, Missouri, pp. 559-566, 2003.
[4] F. Brauer, S. Fahlbusch, J. L. ter Haseborg, and S. Potthast, "Investigation of hardening measures for it equipment against radiated and conducted iemi," IEEE Transactions on Electromagnetic Compatibility, vol. 54, no. 5, pp. 1055-1065, 2012.

[5] R. T. Tientcheu and D. Pouhè, "Susceptibility of generic it-networks," in 2015 International Conference on Electromagnetics in Advanced Applications (ICEAA), pp. 1357-1360, 2015.

[6] M. G. Backstrom and K. G. Lovstrand, "Susceptibility of electronic systems to high-power microwaves: summary of test experience," IEEE Transactions on Electromagnetic Compatibility, vol. 46, no. 3, pp. 396403, 2004.

[7] D. V. Giri and F. M. Tesche, "Classification of intentional electromagnetic environments," IEEE Transactions on Electromagnetic Compatibility, vol. 46, no. 3, pp. 322-328, 2004.

[8] D. Giri, High-power Electromagnetic Radiators: Nonlethal Weapons and Other Applications. Electromagnetics library, Harvard University Press, 2004.

[9] International Electrotechnical Commission, "Electromagnetic compatibility (emc) - part 2-13: Environment - high-power electromagnetic (hpem) environments - radiated and conducted," International Standard IEC 61000-2-13:2005, International Electrotechnical Commission, Geneva, CH, 2005.

[10] G. Lugrin, N. Mora, S. Sliman, F. Rachidi, M. Rubinstein, and R. Cherkaoui, "Overview of iemi conducted and radiated sources: Characteristics and trends," in 2013 International Symposium on Electromagnetic Compatibility, pp. 24-28, 2013.

[11] N. Mora, F. Vega, G. Lugrin, F. Rachidi, and M. Rubinstein, "Study and classification of potential iemi sources," System Design and Assessment Notes, Note 41, 012014.

[12] Telecommunication Standardization Sector of ITU, "High-power electromagnetic immunity guide for telecommunication systems," International Standard ITU-T K.81, International Telecommunication Union, 2016.

[13] N. Mora, G. Lugrin, R. Cherkaoui, F. Rachidi, and M. Rubinstein, "On the vulnerability analysis against iemi," in European Electromagnetics International Symposium EUROEM, Toulouse, France, 072012.

[14] D. Recordon, M. Rubinstein, M. Stojilovic, N. Mora, G. Lugrin, F. Rachidi, L. Rouiller, W. Hirschi, and S. Sliman, "A comparator-based technique for identification of intentional electromagnetic interference attacks," in 2014 International Symposium on Electromagnetic Compatibility, pp. 1257-1262, 2014.

[15] G. M. Loubriel, F. J. Zutavern, A. G. Baca, H. P. Hjalmarson, T. A. Plut, W. D. Helgeson, M. W. O’Malley, M. H. Ruebush, and D. J. Brown, "Photoconductive semiconductor switches," IEEE Transactions on Plasma Science, vol. 25, no. 2, pp. 124-130, 1997.

[16] J. M. Proud and S. L. Norman, "High-frequency waveform generation using optoelectronic switching in silicon," IEEE Transactions on Microwave Theory and Techniques, vol. 26, no. 3, pp. 137-140, 1978.

[17] G. Reineix, J. Hyvernaud, R. Négrier, J. Andrieu, M. Lalande, and V. Couderc, "Design of optoelectronic generators for mesoband conducted effects testing," IEEE Transactions on Electromagnetic Compatibility, pp. 1-6, 2019.

[18] S. Zhang and L. Zhu, "Triple-mode bandpass filters on stub-loaded resonator with novel i/o coupling scheme," in 2012 Asia Pacific Microwave Conference Proceedings, pp. 532-534, 2012.

[19] J. Hong and M. J. Lancaster, Microstrip Filters for RF/Microwave Applications. John Wiley \& Sons, Inc., 2001.

[20] F. Sabath and H. Garbe, "Risk potential of radiated hpem environments," in 2009 IEEE International Symposium on Electromagnetic Compatibility, pp. 226-231, 2009.

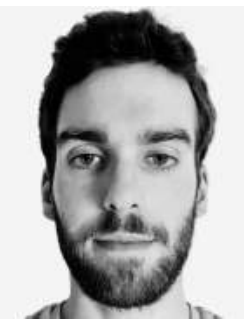

Jérémy Hyvernaud received the Dipl.-Ing. degree in mechatronics from the Engineers School of Limoges, Limoges, France, in 2018. He is currently pursuing the Ph.D. degree from the XLIM Laboratory, University of Limoges, Limoges, France. His research interests include the development of transient signal generators incorporating optoelectronic devices for EMC applications. 

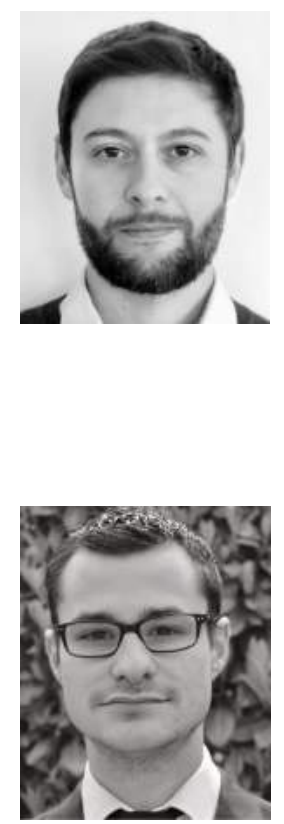

Romain Négrier received the Ph.D. degree in telecommunications engineering from the University of Limoges, Limoges, France, in 2016. For nearly a year, he was a Research Engineer with the Antennas and Microwave Devices Department, IETR, University of Nantes, France. He is currently an Associate Professor with the XLIM Research Institute, University of Limoges. His research interests include wireless sensor network, ultrawideband radar system, and associated processing.

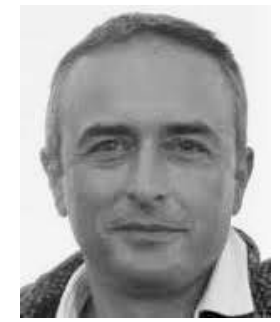

Joël Andrieu received the Ph.D. degree in electronics from the University of Limoges, Limoges, France, in 1990. He is currently a Professor with the University of Limoges and Member of XLIM Research Institute, University of Limoges/National Center For Scientific Research (CNRS), Brive, France. His research interests include ultrawideband metrology for various applications, radar, EMCs, and HPMs.

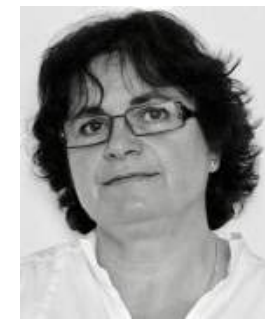

Michèle Lalande received the Ph.D. degree in electronics from the University of Limoges, Limoges, France, in 1986. She is currently a Professor with the University of Limoges and a Member of XLIM Research Institute, University of Limoges/National Center For Scientific Research (CNRS), Brive, France. Her research interests include the area of antennas and transient measurement applications and ultrawideband metrology for various applications: radar and HPMs.

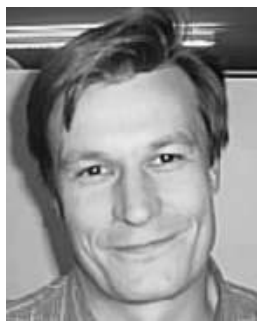

Vincent Couderc received the Ph.D. degree from the University of Limoges, Limoges, France. He is currently the Head of the Photonics Group, XLIM Research Institute, Limoges, France. His research interests include spatial solitons propagation, diodepumped laser source, nonlinear frequency conversion, and optoelectronic switching. Dr. Couderc is a member of the French Optical Society. 